\title{
Point Shear Wave Elastography (pSWE) for Evaluating Relation between Laboratory Renal Function Deterioration in Chronic Kidney Disease (CKD) and Degree of Renal Stiffness
}

\author{
DALIA SALAH EL-DEEN ANWAR, M.D. and ENGY FATHY TANTAWY, M.D.
}

The Department of Radiodiagnosis, Faculty of Medicine, Zagazig University

\begin{abstract}
Aim of Work: To evaluate the role of point shear wave elastography (pSWE) in detecting degree of renal fibrosis and correlating it to deterioration of renal function in chronic kidney disease patients.

Background: Chronic kidney disease (CKD) is diagnosed by either of the following lasting for more than 3 months: Decrease of glomerular filtration rate (GFR) less than $60 \mathrm{ml} / \mathrm{min} / 1.73 \mathrm{~m}^{2}$ which is the best index of kidney function, or presence of markers for kidney damage as albuminuria. Renal fibrosis is nearly the ultimate common pathway for all CKD. The main method in clinical use for the assessment of renal fibrosis is the renal biopsy which is known for its considerable disadvantages like its invasive nature, with a risk of further complications, high cost, inter-observer variability, and sampling error. Shear wave elastography (SWE) is one of the promising techniques that allow non-invasive estimation of tissue stiffness.
\end{abstract}

Material and Methods: This study was performed at the Radiodiagnosis Department, Zagazig University. We examined 42CKD patients who underwent pSWEas well as laboratory detection of Estimated glomerular filtration rate (eGFR). Patients were classified according to GFR into fivestages: Into stage 1 (eGFR $\geq 90$ ), stage 2 (eGFR 60-89), stage 3 (eGFR 30-59), stage 4 (eGFR 15-29), and stage 5 (eGFR <15). All analyses were done using the Statistical Package for theSocial Sciences 20.0 software.

Results: The mean value of SWE (kPa) in CBD patients (5.44 \pm 1.4$)$. The mean SWE values in the CKD stages were $3.65 \pm 0.9,4.5 \pm 1.2,5.8 \pm 0.5,5.3 \pm 1.1,6.6 \pm 0.9 \mathrm{kPa}$ in stages $1,2,3,4$, and 5 respectively. There was no significant difference between CKD stages except between stage 1 vs. 5 and stage 2 vs. 5. Only age showed a significant correlation with SWE in CKD patients ( $r=0.453 ; p=0.039$ ). The laboratory investigationrevealed that 6 patients stage I $(110 \pm 26.5), 8$ patients stage II $(71.5 \pm 1), 8$ patients stage III $(45.5 \pm 8.3), 6$ patients stage IV $(23 \pm 6.2)$ and 14 patients stage V $(8.3 \pm 2.8)$. The cutoff value for predicting CKD was $4.05 \mathrm{kPa}$ with $85.70 \%$ sensitivity and $90.5 \%$ specificity, while for predicting kidney fibrosis it was $4.45 \mathrm{kPa}$ with $93.3 \%$ sensitivity and $83.3 \%$ specificity.

Correspondence to: Dr. Dalia Salah El-Deen Anwar, E-Mail: dodoradiology@ gmail.com
Conclusion: Our results suggest that SWE can distinguish between normal subjects and patients with CKD. It also can detect renal fibrosis but cannot correlate with different CKD stages detected by GFR.

Key Words: Chronic kidney disease - Shear wave elastography - Laboratory - Fibrosis.

\section{Introduction}

CHRONIC kidney disease (CKD) is a chief global public health problem. Its advanced sequela are accompanied by high morbidity and mortality [1] So it is necessary to estimate its severity. CKD is known as the presence of abnormalities of kidney structure or function for more than 3 months, with health implications [2]. It is diagnosed by either of the following, lasting for more than 3 months, decrease of glomerular filtration rate (GFR) less than $60 \mathrm{ml} / \mathrm{min} / 1.73 \mathrm{~m}^{2}$ which is the best index of kidney function, or presence of markers for kidney damage as albuminuria [3]. As CKD develops, it causes extensive tissue destruction, which leads to damage of kidney parenchyma. Renal fibrosis is nearly the ultimate common pathway for all CKD [4], and it is the main cause of kidney structural worsening and function loss [5].

Parenchymal fibrosis is irreversible and can lead to further morbidity and mortality that is why early diagnosis and staging of fibrosis are important to detect prognosis and monitor disease progression. The existence and severity of fibrosis are a valuable predictor for disease evolution in chronic kidney diseases [6]. The gold standard currentimaging method to assess kidney disease is the renal ultrasound measuring the cortical thickness, kidney length and cortical echogenicity. Fibrosis and renal scar burden is assessed by needle biopsy samples [7]. However, renal biopsy has considerable limitations due to its invasive nature, high cost, inter- 
observer variability, and sampling error [8], there is a great interest in developing non-invasive methods to assess renal interstitial fibrosis which is renal ultrasound point shear wave elastography.

Ultrasound-based elastography is one of the most remarkable imaging techniques that evaluate the degree of tissue stiffness in living tissues, giving qualitative and quantitative data [9]. Acoustic Radiation Force Impulse (AFRI), one of the elastography based techniques, assesses the mechanical properties of tissues using short-duration, highintensity pulses of acoustic radiation force to produce localized displacements in tissue and then tracks the tissue dynamic response [10]. Point shear wave elastography (pSWE) using ARFI (Acoustic radiation force impulseimaging) can quantitate tissue elasticity. It is operator-independent using a conventional ultrasound machine with an ordinary ultrasound probe [11].

\section{Patients and Methods}

This study wasestablished after obtaining institutional review board approval and informed consentfrom patients before the study.

\section{Patients:}

The study include 42 CKD patients who underwent laboratory investigation (GFR \& urine albumin) as well as examined by PSWE done at Radiology Department of Zagazig University Hospitals from June 2020 to Mars 2021.

Patients inclusion criteria included: Patients whose age was greater than 18 years and were diagnosed withchronic kidney disease; according to the guidelines established by the Kidney Disease Outcomes Quality Initiative (K/DOQI) of the National Kidney Foundation (NKF), CKD was defined as either kidney damage or e-GFR below $60 \mathrm{ml} /$ $\mathrm{min} / 1.73 \mathrm{~m}^{2}$ for at least 3 months, irrespective of the cause [12], e-GFR was calculated by serum creatinine based on the Modification of Diet in Renal Disease Study (MDRD) equation:

e-GFR $\left(\mathrm{ml} / \mathrm{min} / 1.73 \mathrm{~m}^{2}\right)=186 \times($ Creatinine/ $88.4)-1.154 \times($ Age $)-0.203 \times(0.742$ if female $) \times$ (1.212 if African American) [13].

Then patients were staged according to eGFR into stage 1 (eGFR >-90), stage 2 (eGFR 60-89), stage 3 (eGFR 30-59), stage 4 (eGFR 15-29), and stage 5 (eGFR <15) [14]

Patients exclusion criteria included: Patients whose BMI $>35 \mathrm{~kg} / \mathrm{m}^{2}$ or at any condition that obstructs visualization of the kidney by ultrasound as pregnancy or marked ascites, patients with surgical kidney problems like hydro or pyonephrosis, or patients unwilling to complete the study.

\section{Methods:}

A- Demographic, clinical data and laboratory investigation:

Demographic data including age, sex, and BMI, clinical data, and Laboratory resultsincluding the GFR \& urine albumin test were extracted from medical records or by interview.

\section{$B$-Imaging acquisition:}

Conventional ultrasound and point shear wave elastography examinations were performed by a single experienced ultrasonographer on Philips iU22 Ultrasound machine, (Philips Medical System, Bothell, WA) equipped with ELAST PQ software using C5-1 (1-5 MHz) convex probe.

\section{Conventional US exam:}

The patient was placed in either the supine or lateral decubitus that achievedthe best visualizationof the kidney. A routine conventional ultrasound examination was doneonboth kidneys. On the coronal plane of the kidney, the renal length was measured as the maximum length between superior and inferior poles. Kidney depth was recorded as the distance of the kidney from the skin. Inability to visualize the kidneys in conventional ultrasound for any cause or presence of any renal surgical problems as stones, tumors, or hydronephrosis excluded the person from the study.

\section{SWE Exam:}

Using the Elast PQ software, with the transducer set perpendicular to the renal capsule, regions of interest were placed in the cortex avoiding renal pyramids and blood vessels so that only cortical tissue was included, with specific consideration to keep the ROI parallel to the pyramids as possible. The YMs of the patient's kidney cortex was measured at end-inspiration with patients holding breath.Values were measured at mid kidney and both poles. In case of invalid measurement, the screen displayed $0 \mathrm{KPa}$, we repeated the measurement. At least ten effective measurements were recorded, and the mean value was calculated.

Result correlation with lab. tests:

e-GFR was calculated by serum Creatinine based on the Modification of Diet in Renal Disease Study (MDRD) equation.

Then patients with CKD were staged as follows:

- G1 estimated GFR of greater than $90 \mathrm{~mL} / \mathrm{min}$.

- G2 estimated GFR of 60 to $89 \mathrm{~mL} / \mathrm{min}$. 
- G3 estimated GFR of 30 to $59 \mathrm{~mL} / \mathrm{min}$.

- G4 estimated GFR of 15 to $29 \mathrm{~mL} / \mathrm{min}$.

- G5 estimated GFR of less than $15 \mathrm{~mL} / \mathrm{min}$. [14].

\section{C- Statistical analysis:}

Data analysis was performed using the Statistical Package for the Social Sciences software (IBM Corporation, v. 20.0, Armonk, NY). Data were expressedas numbers and percentages for qualitative data and arithmetic mean \pm Standard deviation (SD) for quantitative data. The differences in demographic features, US measurements, and Lab. values among CKD patients were evaluated by one-way analysis of variance (ANOVA). When differences among them were found to be statistically significant $(p<0.05)$. Influencing factors such as eGFR, age, BMI, kidney length, and kidney depth were analyzed using Pearson's correlation coefficient $(r)$. Diagnostic performance of ARFI in determining CKD and mild fibrosis was assessed using receiver operating characteristic (ROC) curves. The optimal cut-off values were chosen to maximize the sum of sensitivity and specificity. Statistical analysis was performed on the data collected and $p<0.05$ was recognized as statistically significant. The smaller the $p$-value obtained the more significant is the result.

\section{Results}

\section{Patient characteristics:}

42 adults including ( 24 females and 18 males) were assessed. The data of CKD patients are presented in Table (1). There was no significant difference in age, BMI, kidney length, or kidney depth amongthe patients in stages of CKD (Table 2).

Table (1): Demographic features, US measurements, and Lab. values of CKD patients.

\begin{tabular}{lll}
\hline Characteristic & \multicolumn{1}{c}{ CKD } \\
& $\mathrm{N}=42$ & $p^{\mathrm{a}}$ \\
\hline Age (years) & $34 \pm 14.8$ & 0.619 \\
BMI $\left(\mathrm{kg} / \mathrm{m}^{2}\right)$ & $25.6 \pm 2.7$ & 0.072 \\
Kidney length $(\mathrm{cm})$ & $10.4 \pm 1.3$ & 0.776 \\
Kidney depth $(\mathrm{cm})$ & $4.5 \pm 0.9$ & 0.064 \\
YM $(\mathrm{kPa})$ & $5.44 \pm 1.4$ & 0.0001 \\
eGFR $\left(\mathrm{ml} \mathrm{min}\right.$ m $\left.^{-1} / 1.73 \mathrm{~m}^{2}\right)$ & $44.1 \pm 37.7$ & \\
Fibrosis $(\%)$ & $20.5 \pm 19.9$ & \\
\hline
\end{tabular}

Variables are expressed as mean \pm SD.

a One way ANOVA is used to analyze the difference between CKD patients.

* Significant at $p<0.05$.

Table (2): Demographic features, Us measurements, and Lab. values among CKD stages.

\begin{tabular}{lllllll}
\hline Characteristic & CKD1 & CKD2 & CKD3 & CKD4 & CKD5 & \\
& N=6 & N=8 & N=8 & N=14 & $p$ \\
\hline Age (years) & $20.7 \pm 2.1$ & $27.3 \pm 6.6$ & $31.3 \pm 9.2$ & $38.7 \pm 21.2$ & $43.3 \pm 16.7$ & 0.157 \\
BMI $\left(\mathrm{kg} / \mathrm{m}^{2}\right)$ & $23.3 \pm 1.0$ & $26.4 \pm 3.4$ & $25.1 \pm 3.1$ & $26.2 \pm 2.9$ & $26.3 \pm 2.5$ & 0.525 \\
Kidney length $(\mathrm{cm})$ & $11 \pm 0.4$ & $10.5 \pm 1.0$ & $11.3 \pm 0.5$ & $10.1 \pm 1.5$ & $9.7 \pm 1.7$ & 0.352 \\
Kidney depth $(\mathrm{cm})$ & $4.8 \pm 0.3$ & $4.5 \pm 1.0$ & $4.5 \pm 0.9$ & $4.3 \pm 1.3$ & $4.5 \pm 1.0$ & 0.991 \\
YM $(\mathrm{kPa})$ & $3.65 \pm 0.9 \mathbf{a}$ & $4.5 \pm 1.2 \mathbf{a b}$ & $5.8 \pm 0.5 \mathbf{b c}$ & $5.3 \pm 1.1 \mathbf{a b c}$ & $6.6 \pm 0.9 \mathbf{c}$ & 0.002 \\
eGFR $\left(\mathrm{ml} \mathrm{min}{ }^{-1} / 1.73 \mathrm{~m}^{2}\right)$ & $110 \pm 26.5 \mathbf{d}$ & $71.5 \pm 10 \mathbf{c}$ & $45.5 \pm 8.3 \mathbf{b}$ & $23 \pm 6.2 \mathbf{a b}$ & $8.3 \pm 2.8 \mathbf{a}$ & 0.000 \\
Fibrosis $(\%)$ & $6.7 \pm 11.5$ & $13.8 \pm 17.0$ & $18.8 \pm 8.5$ & $20.0 \pm 11.5$ & $19.3 \pm 13.4$ & 0.712 \\
\hline
\end{tabular}

a One way ANOVA is used to analyze the difference between the groups.

- Means with different superscripts (a,b, c, d) are significantly different at $p<0.05$.

\section{Potential influencing factors:}

Age in CKD patients ( $r=0.906 ; p=0.078$ ) showed a significant moderate positive correlation with the SWE. Yet, SWE showed no significant correlation with BMI, kidney length, or kidney depthin CKD patients (Table 3). SWE showed no significant difference between men and women in CKD patients $(5.7 \pm 1.4 \mathrm{kPa}$ vs. $5.3 \pm 1.3 \mathrm{kPa}, p=$ $0.468)$.

\section{SWE in CKD patients:}

The mean value of SWE $(\mathrm{kPa})$ in CKD patients (10.88 \pm 2.8$)$. The mean SWE values in CKD stages were $6.130 \pm 1.8,9.0 \pm 2.4,11.6 \pm 1.0,10.6 \pm 2.2$, and $13.2 \pm 1.8 \mathrm{kPa}$ in stages $1,2,3,4$, and 5 respectively. Despite that the SWE values increased significantly $(p=0.002)$ with the increase of the CKD stage reaching the highest value in patients at stage 5 $(6.6 \pm 0.9 \mathrm{kPa})$, we found no significant difference 
between the different stages of CKD except between stage 1 vs. 5 and stage 2 vs. 5 .

\section{Diagnostic performance of SWE:}

When maximizing the sum of sensitivity and specificity, receiver operating characteristic curve analyses indicated that the area under the ROC curve was 0.956 ( $p<0.0001,95 \%$ CI: 0.902; 01.010). The cut-off value for predicting CKD was $4.05 \mathrm{kPa}$ with a sensitivity of $85.70 \%$ and specificity of $90.5 \%$.

While the optimal cut-off value of SWE imaging was established to be $4.45 \mathrm{kPa}$ for predicting kidney fibrosis with a sensitivity of $93.30 \%$ and specificity of $83.3 \%$. The area under the ROC curve was 0.922 $(p<0.0001,95 \%$ CI: $0.788 ; 01.057)$.
Table (3): Correlation between SWE and different influencing factors in CKD groups.

\begin{tabular}{lcc}
\hline & \multicolumn{2}{c}{ CKD N=42 } \\
\cline { 2 - 3 } Variable & $r$ & $p$ \\
\hline Age (years) & 0.453 & 0.039 \\
BMI $\left(\mathrm{kg} / \mathrm{m}^{2}\right)$ & 0.168 & 0.467 \\
Kidney length $(\mathrm{cm})$ & -0.118 & 0.610 \\
Kidney depth $(\mathrm{cm})$ & -0.203 & 0.377 \\
eGFR $\left(\mathrm{ml} \mathrm{min}^{-1} / 1.73 \mathrm{~m}^{2}\right)$ & -0.637 & 0.002 \\
Stage & 0.749 & 0.000 \\
\hline
\end{tabular}

- Correlation between SWE and variables are analyzed using Pearson's Correlation coefficient.
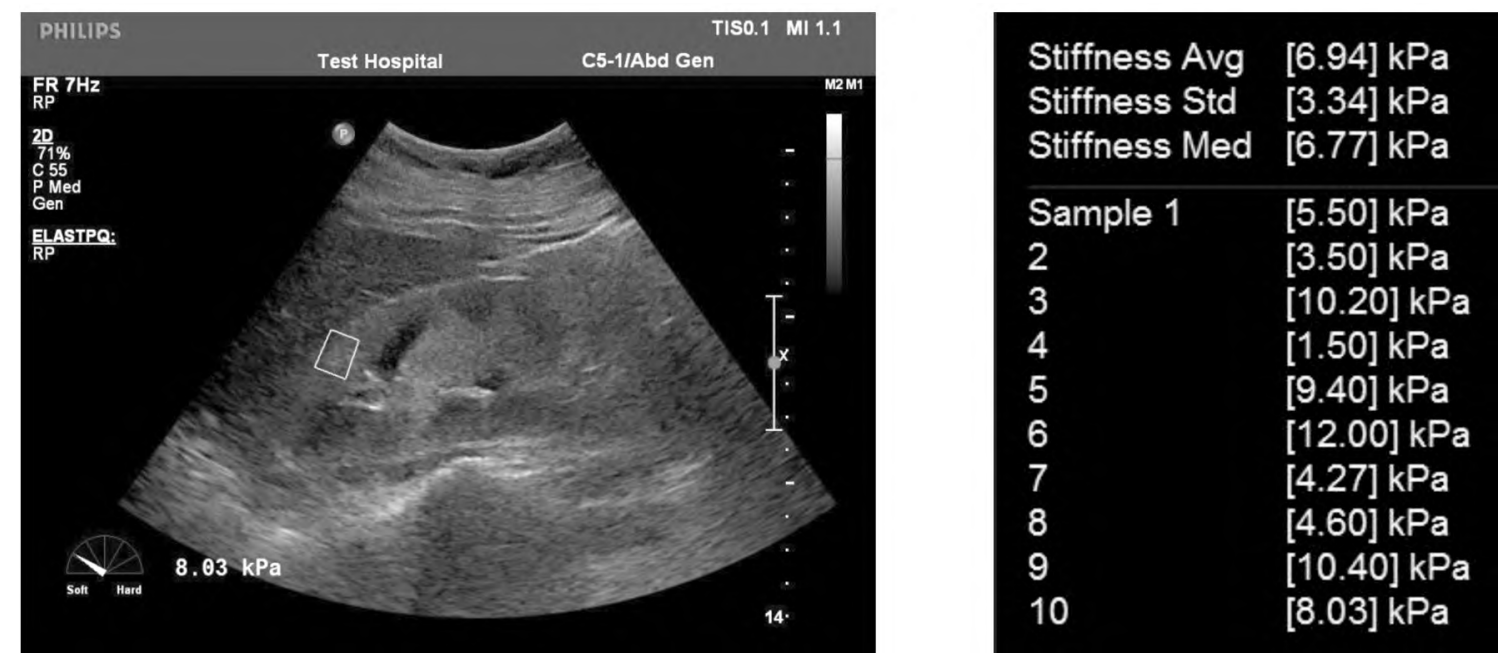

Fig. (1): A 20-year-old female patient with chronic kidney disease.Creatinine $=10.5 \mathrm{mg} / \mathrm{dl}, \mathrm{GFR}=5 \mathrm{ml} / \mathrm{min}$ (stage 5) Right kidney: Normal site, shape, and size (measures $12 \times 4.8 \mathrm{~cm}$ ) and normal cortical thickness (measures about $1.5 \mathrm{~cm}$ ). It showed increased cortical echogenicity (grade II to III echogenicity) and good cortico medullary differentiation (CMD). Grade I nephropathy. Right kidney Stiffness mean YM value=6.94kPa.
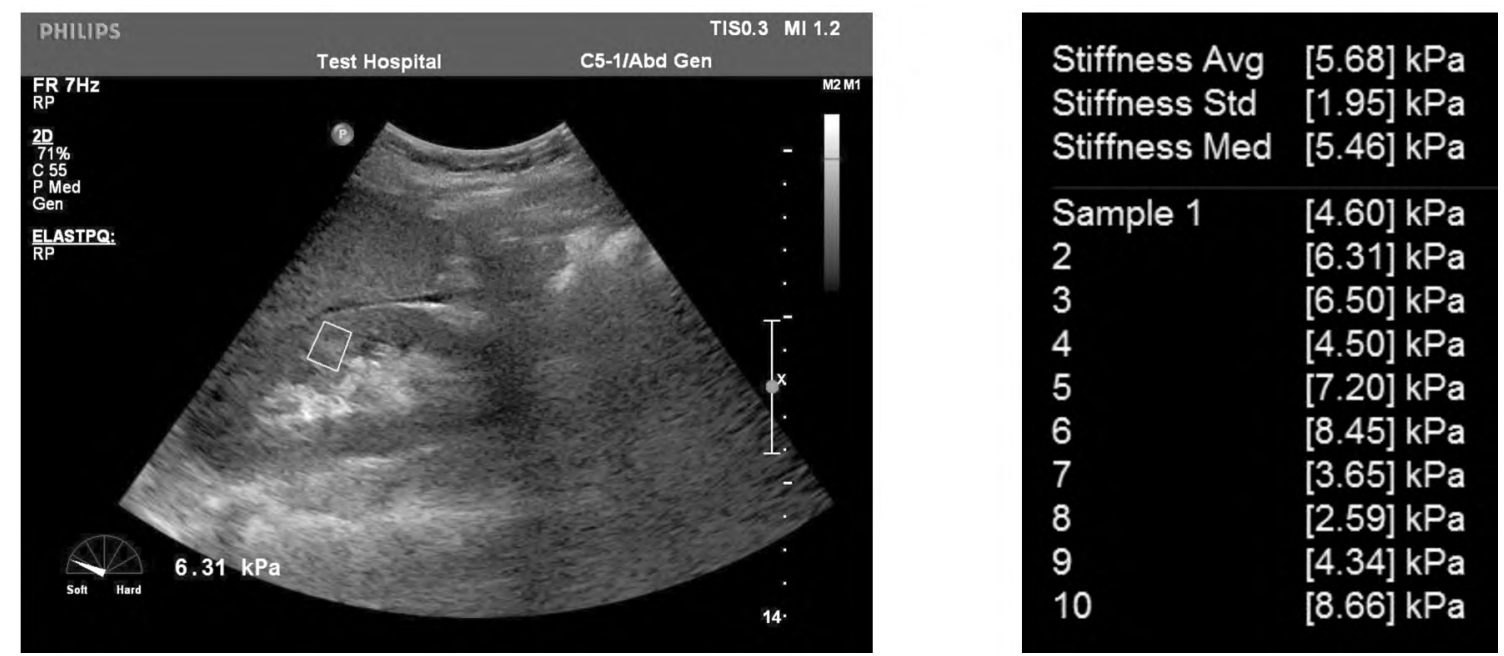

Fig. (2): LT kidney of the same patient shows Showed normal site, shape, and size (measures $12.2 \times 4.7 \mathrm{~cm}$ ) and normal cortical thickness (measures about $1.8 \mathrm{~cm}$ ). It showed increased cortical echogenicity (grade III echogenicity) and good CMD. Left kidney stiffness mean $\mathrm{YM}$ value $=7.5 \mathrm{kPa}$. 

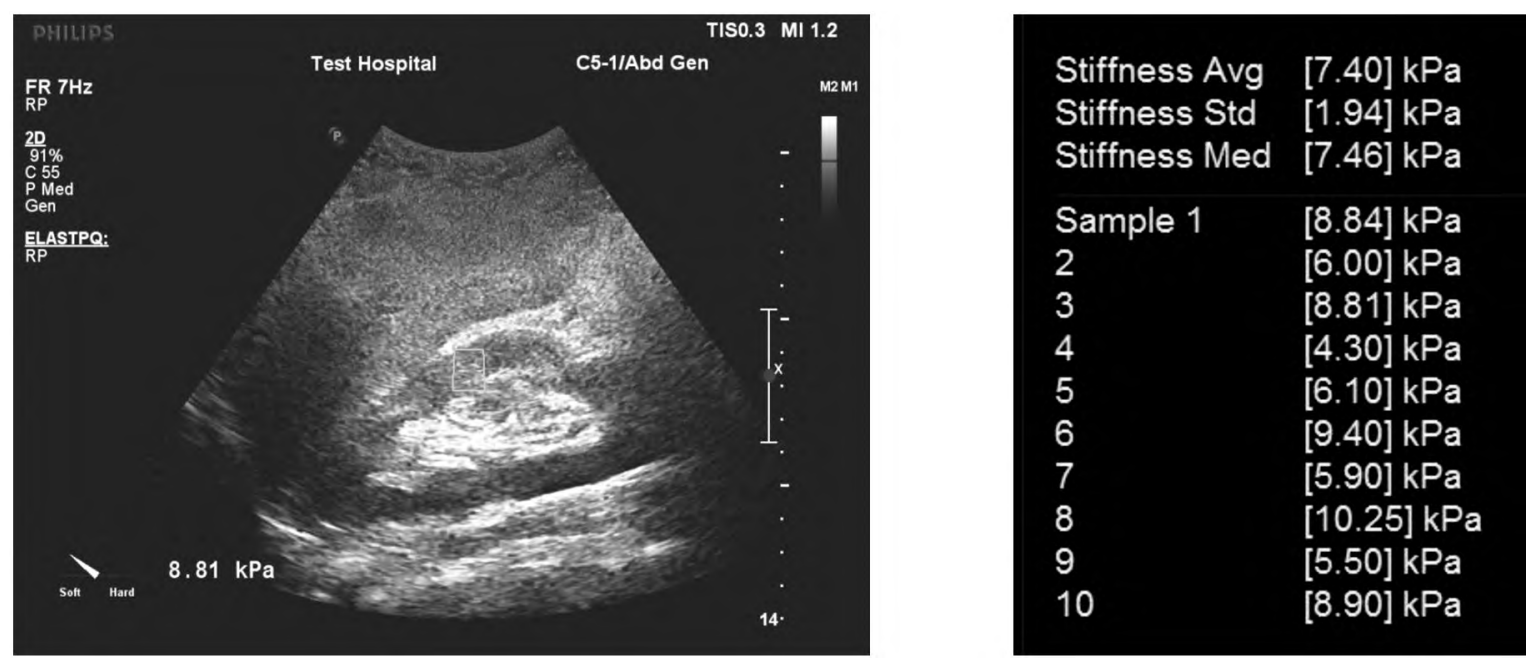

Fig. (3): A 26-year-old female patient with chronic kidney disease, BMI is 25.9 Creatinine $=4.69 \mathrm{mg} / \mathrm{dl}-\mathrm{GFR}=12 \mathrm{ml} / \mathrm{min}$ ( $\mathrm{stage}$ 5) Right kidney: Showed normal site, shape, and size (measures $10.8 \mathrm{x} 4.5 \mathrm{~cm}$ ) and normal cortical thickness (measures about $1.5 \mathrm{~cm}$ ). It showed normal cortical echogenicity and good CMD. Right kidney Stiffness mean YM value=7.4kPa.
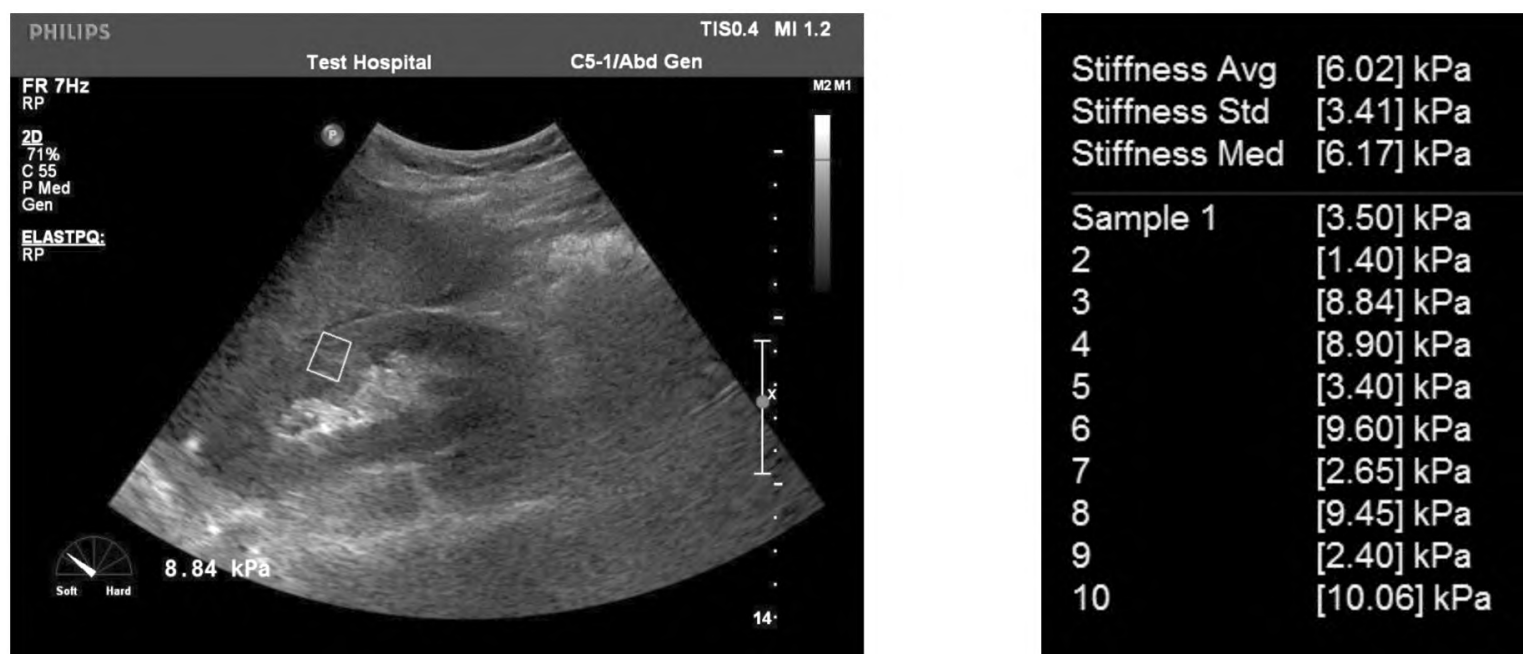

Fig. (4): Left kidney of the same patient: Showed normal site, shape, and size (measures $11 \mathrm{x} 4.2 \mathrm{~cm}$ ) and normal cortical thickness (measures about $1.5 \mathrm{~cm}$ ). It showed normal cortical echogenicity and good CMD. Left kidney stiffness mean YM value= $6.02 \mathrm{kPa}$.

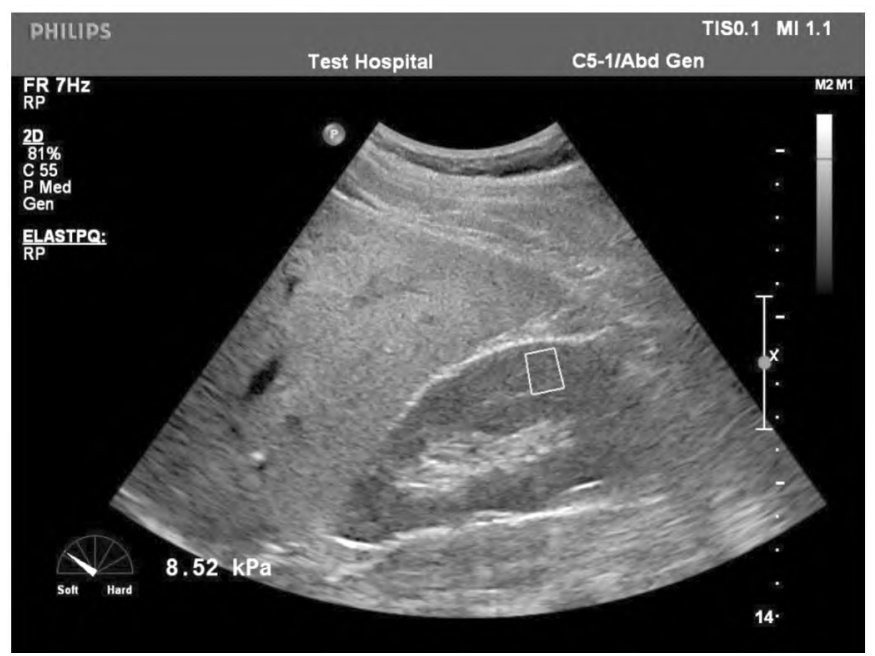

\begin{tabular}{ll} 
Stiffness Avg & {$[7.60] \mathrm{kPa}$} \\
Stiffness Std & {$[2.23] \mathrm{kPa}$} \\
Stiffness Med & {$[7.51] \mathrm{kPa}$} \\
\hline Sample 1 & {$[6.50] \mathrm{kPa}$} \\
2 & {$[8.60] \mathrm{kPa}$} \\
3 & {$[6.40] \mathrm{kPa}$} \\
4 & {$[8.52] \mathrm{kPa}$} \\
5 & {$[10.40] \mathrm{kPa}$} \\
6 & {$[5.62] \mathrm{kPa}$} \\
7 & {$[9.15] \mathrm{kPa}$} \\
8 & {$[3.70] \mathrm{kPa}$} \\
9 & {$[5.91] \mathrm{kPa}$} \\
10 & {$[11.20] \mathrm{kPa}$}
\end{tabular}

Fig. (5): A 65 years old male patient with chronic kidney disease and history of HCV. His BMI was 23.7. Creatinine=7.3mg/dlGFR $=8 \mathrm{ml} / \mathrm{min}$ (stage 5).Right kidney: Showed normal site, shape, and size (measures $10.7 \mathrm{x} 4.3 \mathrm{~cm}$ ) and normal cortical thickness (measures about $1.6 \mathrm{~cm}$ ). It showed normal cortical echogenicity and good CMD. 


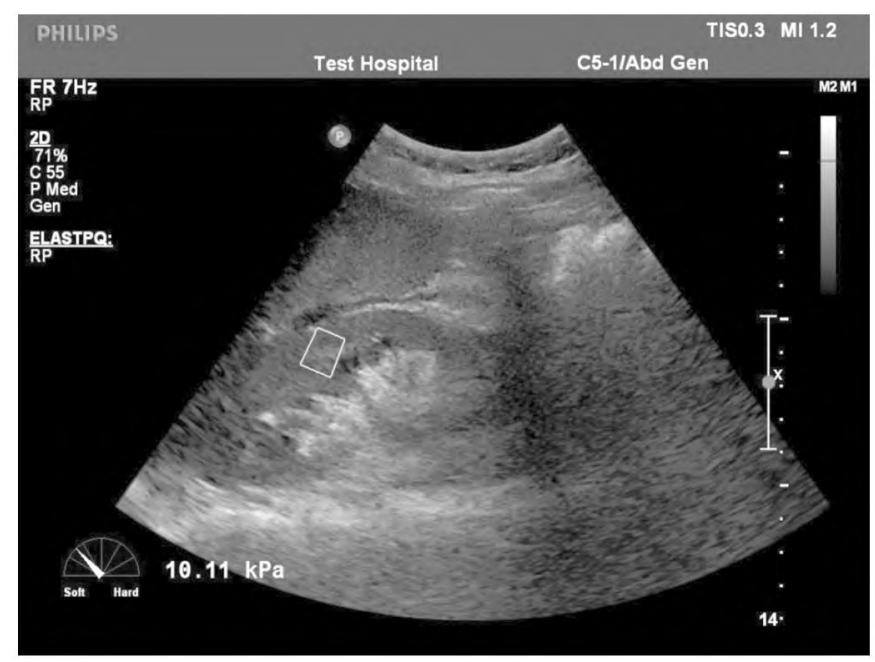

\begin{tabular}{ll} 
Stiffness Avg & {$[8.58] \mathrm{kPa}$} \\
Stiffness Std & {$[3.04] \mathrm{kPa}$} \\
Stiffness Med & {$[8.28] \mathrm{kPa}$} \\
\hline Sample 1 & {$[6.45] \mathrm{kPa}$} \\
2 & {$[6.23] \mathrm{kPa}$} \\
3 & {$[10.11] \mathrm{kPa}$} \\
4 & {$[10.45] \mathrm{kPa}$} \\
5 & {$[5.84] \mathrm{kPa}$} \\
6 & {$[11.60] \mathrm{kPa}$} \\
7 & {$[12.45] \mathrm{kPa}$} \\
8 & {$[3.90] \mathrm{kPa}$} \\
9 & {$[6.10] \mathrm{kPa}$} \\
10 & {$[12.67] \mathrm{kPa}$}
\end{tabular}

Fig. (6): Left kidney of the same patient: Showed normal site, shape, and size (measures $10.7 \mathrm{x} 4.2 \mathrm{~cm}$ ) and normal cortical thickness (measures about $1.4 \mathrm{~cm}$ ). It showed normal cortical echogenicity and good CMD. Left kidney stiffness mean YM value $=8.58 \mathrm{kPa}$.
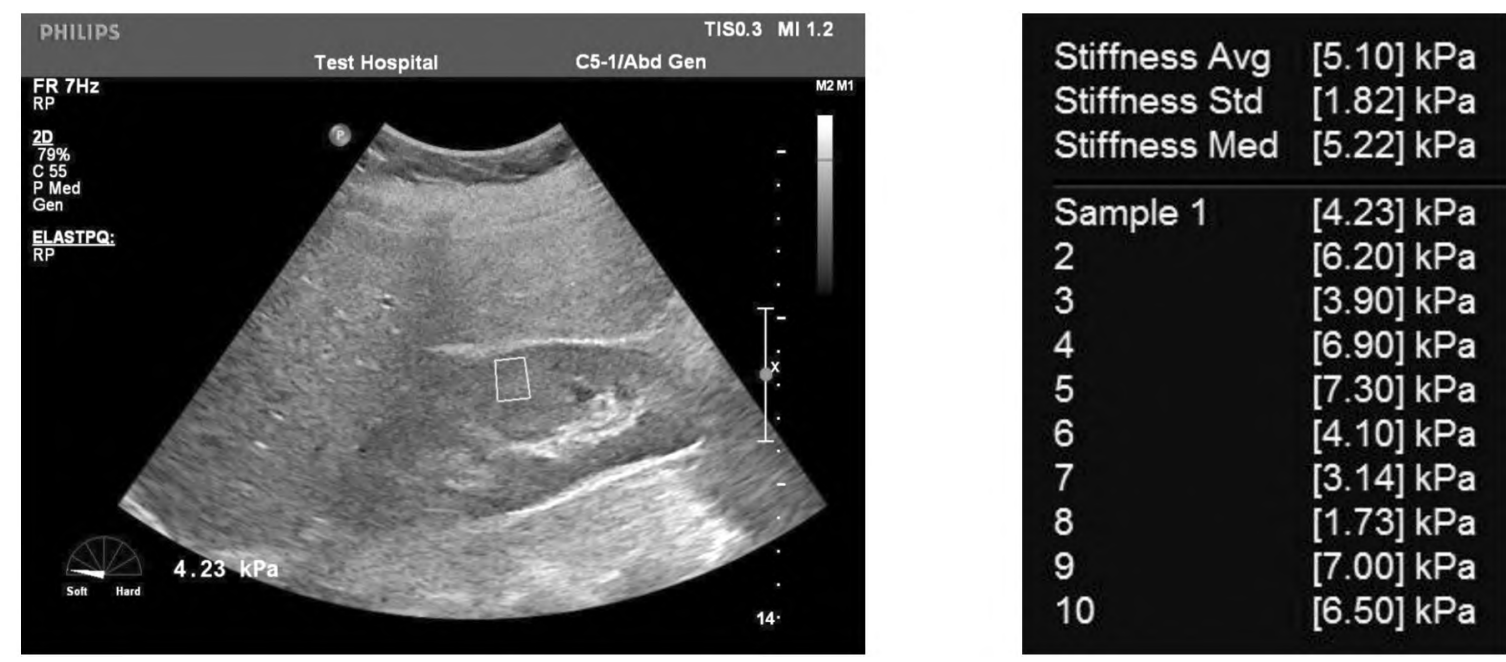

Fig. (7): A 63-year-old male patient with chronic kidney disease and hypertension. His BMI is 26.1. Creatinine $=2.75 \mathrm{mg} / \mathrm{dl}-$ GFR=25 ml/min (stage 4). Right kidney: Showed normal site, shape, and size (measures 11.4 x $4.2 \mathrm{~cm}$ ) and normal cortical thickness (measures about $1.2 \mathrm{~cm}$ ). It showed slightly increased cortical echogenicity and good CMD. Right kidney Stiffness mean YM value=5.1kPa.
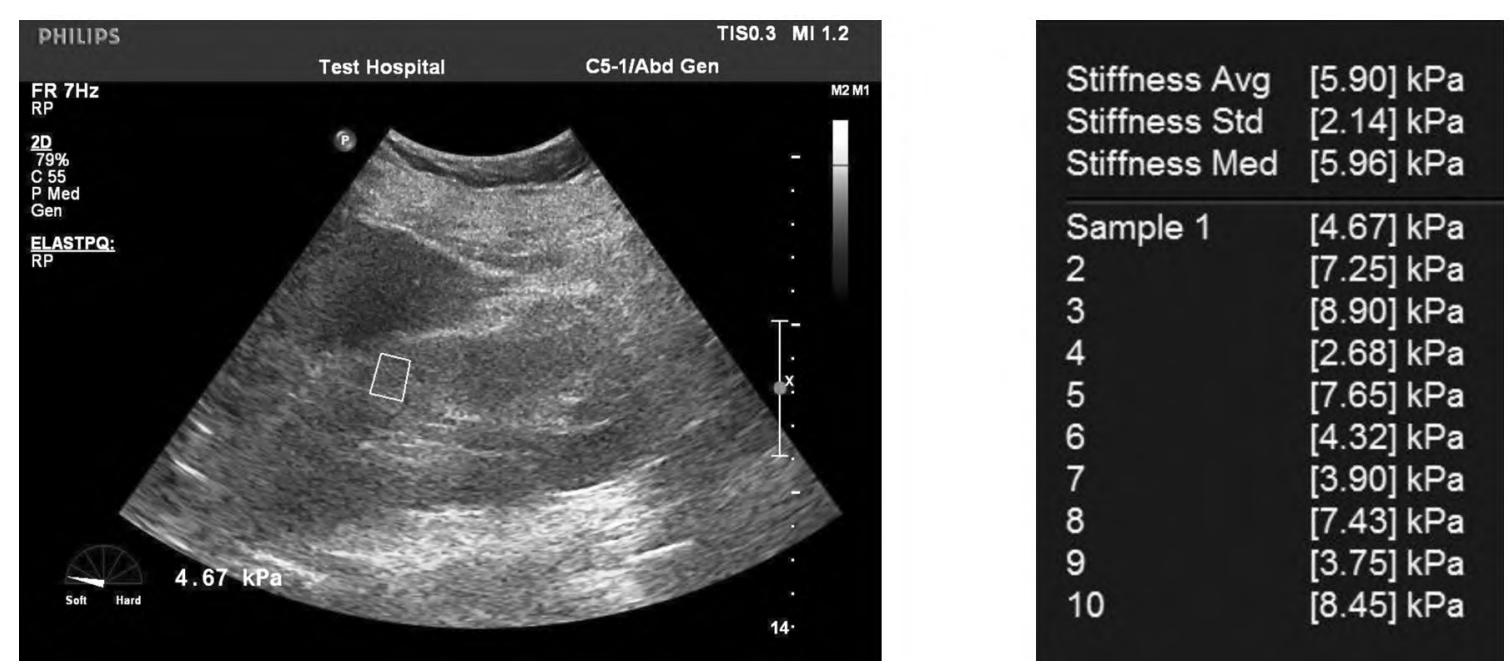

Fig. (8): Left kidney of the same patient: Showed normal site, shape, and size (measures $11.6 \times 4.5 \mathrm{~cm}$ ) and normal parenchymal thickness (measures about $1.5 \mathrm{~cm}$ ). It showed increased cortical echogenicity (grade I echogenicity) and fair CMD. Left kidney stiffness mean YM value= $=5.9 \mathrm{kPa}$. 


\section{Discussion}

We first investigated the role of ARFI to detect cortical stiffness in patients with CKD. Our results showed that there is a positive correlation between renal cortical stiffness estimated by Young's modulus (YM) values and the presence of CKD. This was in agreement with other ARFI studies that reported a positive correlation between the presence of CKD and renal cortical stiffness measured by both YM (Leong et al., (2018) [15] and Leong et al., (2019) [16]) and by shear wave velocity (SWV) (Peride et al., (2016b) [17]). In addition to supersonic shear imaging (SSI) studies done by Samir et al. (2015) [18] and Radulescu et al., (2019) [19] who reported that SWE measurements in CKD patients were significantly higher than in healthy volunteers.

Among the studies that were performed on human adult native kidneys using SWE techniques and compared between healthy and CKD patients, we noticed that the majority of the studies that used YM values showed a positive correlation between the presence of CKD and renal cortical stiffness [Samir et al., (2015), Leong et al., (2018), Diep S (2019) [20], Radulescu et al., (2019), and Leong et al., (2019)], apart from Danse et al. (2017) [21] who reported no correlation between the presence of CKD and SWE. However, most of the studies that used SWV measurements showed negative correlation (Guo et al., (2013), Hu et al. (2014), Bob et al., (2015), and Grosu et al., (2017) [22]) or no correlation [Wang et al., (2014), Gao et al., (2017)] between the presence of CKD and SWV measurements. The reason for this contrast is indistinct.

When comparing our results with the results from similar studies as Leong et al., (2018) and Leong et al., (2019) who used ARFI techniques on human adult native kidneys and used YM measurements, we noticed a significant difference between estimated YM values in CKD patients. The Mean YM values in our study were $3.65 \pm 0.9$, $4.5 \pm 1.2,5.8 \pm 0.5,5.3 \pm 1.1$, and $6.6 \pm 0.9$ in $\mathrm{CKD}$ stage $1,2,3,4$, and 5 respectively with the mean value $5.44 \pm 1.4$. While in the study done by Leong et al., (2018), the mean YM values were $7.61 \pm 6.09$, $11.61 \pm 6.88,10.06 \pm 5.72,12.75 \pm 5.63$ in CKD stage $2,3,4,5$ respectively. There is a consider able difference between the YM values in CKD in our study and the study done by Leong et al., (2018). However, when comparing the ROC analysis, the cut-off values of the YM measurements that distinguish healthy kidneys from those with CKD [ $4.05 \mathrm{kPa}$ in our study and $4.31 \mathrm{kPa}$ in Leong et al.,
(2018)] were very close. So the higher YM values in CKD cases in Leong et al., (2018) could be explained by the higher number of cases included in Leong et al., (2018) study or may be due to the lack of standardized methodology and technique as reviewed by Bruno et al., (2015) [23], Peride et al., (2016b), and Radulescu et al., (2019).

This discrepancy in the result occurred also in the studies that used SSI techniques and YM measurements; the YM values in Radulescu et al., (2019) were much higher than those of Samir et al., (2015), as well as in the studies that used ARFI techniques and SWV measurements, the SWV values in Bruno et al., (2013) were much higher than those of Göya et al., (2015b) [24], despite using the same technique and studying similar population.

Moreover, in our study, a significant moderate negative correlation was observed between YM values and eGFR ( $r=-0.637, p<0.002)$. Similar results were demonstrated in Leong et al., (2018) $(r=-0.576, p<0.0001)$ and Leong et al., (2019), who used radiolabeled GFR measurements, ( $r=-0.690, p<0.0001)$. This strengthens the theory that the change in renal cortical stiffness could be a sign of CKD.

We found no significant difference in renal cortical stiffness between the stages of CKD except between stage 1 vs. 5 and stage 2 vs. 5 . This is in agreement with Leong et al. (2018) who reported that there was no significant difference between CKD stages 3, 4, and 5. Peride et al., (2106b) also reported no difference between stages of CKD. While Bob et al., (2015) described only a significant difference between stages 1 and 2 vs. 4 and 1 and 2 vs. 5 . These differences may be due to the difference in the number of subjects included in each study or the variability of the number of patients among CKD stages.

We additionally investigated the role of some potential influencing factors on SWE as age, gender, BMI, kidney length, and kidney depth. We found no significant difference in any of those studied factors between the different stages of CKD groups. Among the studied factors, age was the only factor that had an association with estimated renal cortical stiffness in CKD patients. Peride et al., (2016b) and Leong et al., (2018) also reported a positive correlation between age and cortical stiffness. This could be explained by the development of glomerulosclerosis, tubular atrophy, interstitial fibrosis, and arteriosclerosis with aging. However, Samir et al., (2015) and Radulescu et al., (2019) recently reported no significant correlation between YM measurements and age. 
We observed that patients with renal fibrosis showed significantly higher YM values than those with no fibrosis $(p<0.01)$. There are significantly higher YM values in cases with mild fibrosis than those with no fibrosis, but there is no significant difference between cases with mild and moderate degrees of fibrosis. This observation is supported by Cui et al., (2013) [25] who reported significantly higher SWE values in mild and moderate fibrosis groups than in the non-fibrosis group, while no difference between the values in mild and moderate fibrosis groups and Venkatachalam et al., (2020) [26] who reported higher values of SWE in patients with fibrosis than those with no fibrosis. In contrast to our study, Wang et al., (2014) declared that SWE measurements showed no correlation with any of the pathological indicators of fibrosis in patients with CKD. This contrast may be explained by the presence of structural heterogeneity of renal parenchyma or may be that renal fibrosis is not the only factor that affects the stiffness of the tissue at the level of the kidney as reported by Wang et al., (2014) or SWE measurements are influenced by the renal blood flow as described Asano et al., (2014).

According to the ROC analysis in our study, a cut-off $4.45 \mathrm{kPa}$ was determined to differentiate between kidney fibrosis and non-fibrosis with a sensitivity of $93.3 \%$ and a specificity of $83.3 \%$; suggesting a diagnostic reference for renal fibrosis.

When comparing our results, we found that a cut-off value of $4.05 \mathrm{kPa}$ or more could differentiate CKD patients from healthy volunteers while a cutoff of $4.45 \mathrm{kPa}$ could differentiate kidney fibrosis from non-fibrosis. These close values may suggest that renal fibrosis may be a probable reason for the increase of renal cortical stiffness in CKD.

Our study faced some limitations that should be mentioned as the small number of participants included in the study, the study was performed by one radiologist, the limited detection depth of the SWE method prevented us from recruiting obese patients and patients with hepatomegaly or splenomegaly, fixed ROI volume made us exclude patients with thin renal parenchyma from the study, holding breath was difficult for most of the patients and the sensitivity to breathing movement artifact was one of the challenges to obtain reliable measurements.

Conclusion: In conclusion, our results suggest that SWE can distinguish between normal subjects and patients with CKD. SWE also can detect renal fibrosis in patientswith CKD. Despite it can't distinguish between the stages of CKD or the degrees of renal fibrosis, In future studies, we suggest including more influencing factors like renal blood flow and the influence of the SWE technique used by making a comparison between the values obtained by different techniques on the same population.

\section{References}

1- GO A.S., CHERTOW G.M., FAN D., McCULLOCH C.E. and HSU C-Y.: Chronic kidney disease and the risks of death, cardiovascular events, and hospitalization. New England Journal of Medicine, 351 (13): 1296-305, 2004.

2- KDIGO 2018 Clinical Practice Guideline for the Prevention, Diagnosis, Evaluation, and Treatment of Hepatitis $\mathrm{C}$ in Chronic Kidney Disease. Kidney International Supplements, 8 (3): 91-165, 2018.

3- LEVEY A.S. and CORESH J.: Chronic kidney disease. Lancet (London, England), 379 (9811): 165-80, 2012.

4- EDDY A.A.: Experimental insights into the tubulointerstitial disease accompanying primary glomerular lesions. Journal of the American Society of Nephrology, 5 (6): 1273-87, 1994.

5- BOOR P., SEBEKOVÁ K., OSTENDORF T. and FLOEGE J.: Treatment targets in renal fibrosis. Nephrology, dialysis, transplantation: Official publication of the European Dialysis and Transplant Association = European Renal Association, 22 (12): 3391-407, 2007.

6- KLINKHAMMER B.M., GOLDSCHMEDING R., FLOEGE J. and BOOR P.: Treatment of Renal FibrosisTurning Challenges into Opportunities. Advances in chronic kidney disease, 24 (2): 117-29, 2017.

7- SCHAINUCK L.I., STRIKER G.E., CUTLER R.E. and BENDITT E.P.: Structural-functional correlations in renal disease. II. The correlations. Human pathology, 1 (4): 631-41, 1970.

8- MANNING D.S. and AFDHAL N.H.: Diagnosis and quantitation of fibrosis. Gastroenterology, 134 (6): 167081, 2008.

9- LI G-Y. and CAO Y.: Mechanics of ultrasound elastography. Proceedings of the Royal Society A: Mathematical, Physical and Engineering Sciences, 473 (2199): 20160841, 2017.

10- GENNISSON J.L., DEFFIEUX T., FINK M. and TANTER M.: Ultrasound elastography: Principles and techniques. Diagnostic and Interventional Imaging, 94 (5): 487-95, 2013.

11- FRIEDRICH-RUST M., NIERHOFF J., LUPSOR M., SPOREA I., FIERBINTEANU-BRATICEVICI C., STROBEL D., et al.: Performance of Acoustic Radiation Force Impulse imaging for the staging of liver fibrosis: A pooled meta-analysis. Journal of viral hepatitis, 19 (2): e212-9, 2012.

12- K/DOQI clinical practice guidelines for chronic kidney disease: evaluation, classification, and stratification. American journal of kidney diseases: The official journal of the National Kidney Foundation, 39 (2 Suppl 1): S1266, 2002. 
13- LEVEY A.S., CORESH J., GREENE T., STEVENS L.A., ZHANG Y.L., HENDRIKSEN S., et al.: Using standardized serum creatinine values in the modification of diet in renal disease study equation for estimating glomerular filtration rate. Ann. Intern. Med., 145 (4): 247-54, 2006.

14- LEVEY A.S., STEVENS L.A., SCHMID C.H., ZHANG Y.L., CASTRO A.F., 3 rd, FELDMAN H.I., et al.: A new equation to estimate glomerular filtration rate. Ann. Intern. Med., 150 (9): 604-12, 2009.

15- LEONG S.S., WONG J.H.D., MD SHAH M.N., VIJAYANANTHAN A., JALALONMUHALI M. and NG K.H.: Shear wave elastography in the evaluation of renal parenchymal stiffness in patients with chronic kidney disease. The British Journal of Radiology, 91 (1089): 20180235, 2018.

16- LEONG S.S., WONG J.H.D., SHAH M.N.M., VIJAYANANTHAN A., JALALONMUHALI M. and NG K.H.: Comparison of Shear Wave Elastography and Conventional Ultrasound in Assessing Kidney Function as Measured Using 51Cr-ethylenediaminetetraacetic Acid and 99TcDimercaptosuccinic Acid. Ultrasound in Medicine \& Biology, 45 (6): 1417-26, 2019.

17- PERIDE I., RA DULESCU D., NICULAE A., ENE V., BRATU O.G. and CHECHERITA I.A.: Value of ultrasound elastography in the diagnosis of native kidney fibrosis. Medical Ultrasonography, 18 (3): 362-9, 2016.

18- SAMIR A.E., ALLEGRETTI A.S., ZHU Q., DHYANI M., ANVARI A., SULLIVAN D.A., et al.: Shear wave elastography in chronic kidney disease: A pilot experience in native kidneys. BMC nephrology, 16: 119, 2015.

19- RADULESCU D., PERIDE I., PETCU L.C., NICULAE A. and CHECHERITA I.A.: Supersonic shear wave ultrasonography for assessing tissue stiffness in native kidney. Ultrasound in Medicine \& Biology, 44 (12): 2556-68, 2018.
20- DIEP S.: A comparison of normal kidneys to those with chronic kidney disease using ultrasound shearwave elastography. Ultrasound in Medicine and Biology, 45: S88, 2019.

21- DANSE E., LENFANT C., JADOUL M., HOUSSIAU F., AYDIN S., COSYNS J.P., et al., editors.: Elastography point quantification and chronic renal diseases 2017: European Congress of Radiology-ECR 2017.

22- GROSU I., BOB F., SPOREA I., POPESCU A., S IRLI R. and SCHILLER A.: Correlation of point shear wave velocity and kidney function in chronic kidney disease. Journal of Ultrasound in Medicine, 37 (11): 2613-20, 2018.

23- BRUNO C., CALIARI G., ZAFFANELLO M., BRUGNARA M., ZUFFANTE M., CECCHETTO M., et al. Acoustic radiation force impulse (ARFI) in the evaluation of the renal parenchymal stiffness in paediatric patients with vesicoureteral reflux: Preliminary results. European Radiology, 23 (12): 3477-84, 2013

24- GÖYA C., HAMIDI C., ECE A., OKUR M.H., TAS DEMIR B., ÇETINÇAKMAK M.G., et al.: Acoustic radiation force impulse (ARFI) elastography for detection of renal damage in children. Pediatric Radiology, 45 (1): 55-61, 2015.

25- CUI G., YANG Z., ZHANG W., LI B., SUN F., XU C., et al.: Evaluation of acoustic radiation force impulse imaging for the clinicopathological typing of renal fibrosis. Experimental and Therapeutic Medicine, 7 (1): 233-5, 2014.

26- VENKATACHALAM K., SHETTY M. and SHETTY S.: SUN-158 Non Invasive Evaluation of Native Kidney Fibrosis-A Study On The Correlation of Shear Wave Elastography Of The Native Kidneys With Renal Histopathology. Kidney International Reports, 5 (3): S265, 2020. 


\section{استخخدام التصوير الالستوجرافى لموجة القص النقطية

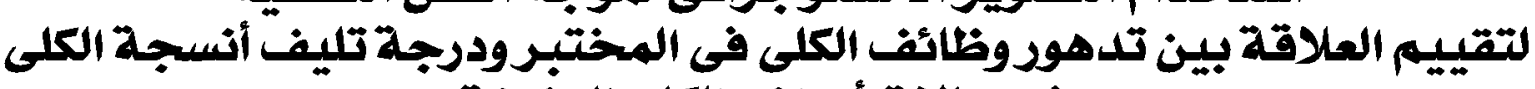

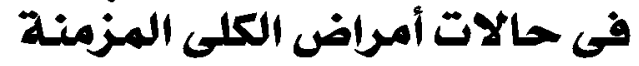

المقدمة: تعتبر أمراض الكلى المزمنة واحدة من أهم المشكلات المصية العالمية وذلك لارتباطها بمعدلات الاعتلال والوفيات العالية ولذلك

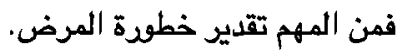

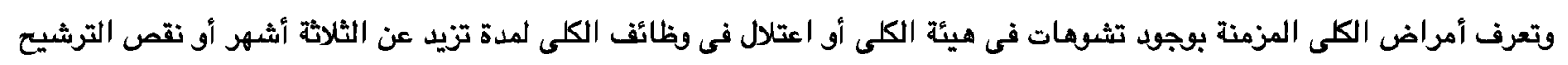

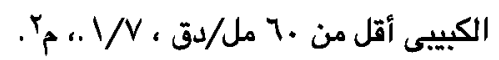

تطود أمراض الكلى المزمنة يؤدى إلى ثدمير أنسجة الكلى على نطاق واسع ويعتبر تليف أنسجة الكلى هو المسار المثترك النهائى لكل أمراض الكلى المزمنة.

تليف الكلى لا رجعة فيه وتزيد من معدلات الاعتلال والوفيات لذلك التشخيص المبكر وتحديد درجة التيف هى خطوة مهمة لرصد المرض وتشخيص درجة تطورة.

تحديل وجود وثشدة درجة تليف أنسجة الكلى تستطيع التنبؤ بأمراض الكلى.

يعتبر التصوير بالاشعة التلفزيونية وقياس السمك القشىى للكلى قأخذ عينة من الأنسجة هى أفضل الوسيائل لتشخيص درجة إصابة الكلى

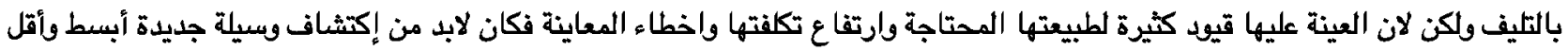
خطورة لتحديد درجة تليف الكلى الهدف من الدراسة: تقييم دور التصوير الالستوجرافى فى الكثف وتقييم درجة التيف الكلوى، وارتباطه بتدهو وظائف الكلى فى حالات الأمراض الكلوية المزمنة. 